\title{
Capacity to consent to treatment in patients with acute mania
}

\section{AIMS AND METHOD}

This study aimed to determine the proportion of patients hospitalised with mania who had capacity to consent to treatment, to determine the predictors of capacity and to explore the relationship between detained status and capacity. Fifty in-patients with mania participated

\author{
in a clinical interview to assess \\ capacity.
}

\author{
RESULTS \\ Nineteen patients (38\%) had overall \\ capacity. Capacity was predicted by \\ higher IQ, lower severity of manic \\ symptoms and more episodes of \\ depression; it was not related to \\ voluntary or detained status. The
}

\author{
domains of capacity were not \\ hierarchical. \\ CLINICAL IMPLICATIONS \\ Many patients hospitalised with \\ mania have capacity to make an \\ informed choice regarding treatment \\ even when compulsorily detained. \\ Their capacity should be reviewed \\ frequently and measures adopted to \\ enhance capacity.
}

The involvement of people with mental illness in making decisions about their treatment is becoming increasingly important. This principle is highlighted both in the guidelines issued by the National Institute for Clinical Excellence (2002) and in the revised Draft Mental Health Bill (Department of Health, 2004). However, the ability to collaborate in treatment decisions depends upon the person's capacity and this is frequently adversely affected by the presence of mental illness. The capacity of patients with schizophrenia has been extensively studied and has shown a broad range, from significantly impaired to full capacity in both the acute (Geller, 1982; Grisso \& Appelbaum, 1995) and chronic (Eastwood \& Pugh, 1997) stages of the illness. In-patients with depression have shown relatively unimpaired capacity (Grisso \& Appelbaum, 1995). Patients with bipolar disorder have not been studied.

This study had the primary aim of determining the proportion of hospitalised patients with acute mania who had capacity to consent to acute drug treatment. Secondary aims were to investigate the factors that predict whether a patient has capacity, to explore the relationship between detained status and capacity to consent to treatment and to investigate whether there is a hierarchical relationship between the domains of capacity.

\section{Method}

In-patients with an ICD-10 (World Health Organization, 1992) diagnosis of bipolar affective disorder, current episode manic with or without psychosis, were recruited from a psychiatric hospital. All in-patients aged 18-75 years with a possible diagnosis of mania from case notes were assessed for eligibility by one of two specialist registrars in psychiatry. The diagnosis was confirmed by reference to the case notes and following discussion with the clinical team. Patients with an unclear diagnosis, a diagnosis of schizoaffective disorder or those predicted to have a low Young Mania Rating Scale score (YMRS;
Young et al, 1978) were excluded. Patients were approached during the first few days of admission and those unable to give informed consent to enter the study were approached at a later date after clinical improvement.

Each patient was interviewed by a specialist registrar. Initially, the YMRS was administered and those scoring 20 or more proceeded with the rest of the interview. Administration of the National Adult Reading Test (NART; Nelson, 1982) yielded a premorbid estimation of IQ. From this interview (and from perusal of the case notes) the following data were obtained: basic demographic details; voluntary or detained status; length of illness; number of illness episodes; alcohol (units) and illicit substances consumed in the week preceding admission; and educational level achieved.

Each patient's capacity to consent to their treatment was assessed using a clinical interview based on the definition of capacity as laid out in the Code of Practice of the Mental Health Act 1983 (Department of Health, 1999) and the British Medical Association and Law Society Guidelines (British Medical Association \& Law Society, 1995). The assessment was designed to give a global judgement of capacity based on a clinical interview. Personalised information about diagnosis, treatment and its risks and benefits was initially disclosed to the patient. The following information was disclosed: three prominent features of the illness, one current medication (preferably a mood stabiliser) and two current (or potential) sideeffects experienced by the patient.

Capacity was then assessed along four separate domains. These domains were:

(a) The ability to retain the information given to them in the disclosure. Patients had to recall at least two out of three features of the illness, the medication they were taking and one of the two possible side-effects given in the disclosure.

(b) The ability to understand the information disclosed relevant to making a decision about treatment. To assess this domain, the following questions relating to the disclosure were asked: 'Do you believe that this 


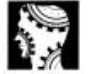

original papers situation relates to you?', 'To what extent does it apply to you?' and 'What do you understand of your situation?"

(c) The ability to reason, to weigh up the information in the balance as part of a process of arriving at a decision about their treatment. To assess this domain, the following questions relating to the disclosure were asked: 'What effect do you think the treatment will have on you?', 'If you stopped your medication, what do you think might happen?', Have you thought about alternative treatments? If so, what?'

(d) The ability to communicate a decision about treatment. The following question was asked to assess this domain: 'Now that we've had a discussion about your treatment, are you happy to stay on your medication?'

Initially we included an additional domain, relating to patients' ability to believe that the information disclosed applied to them. This domain was later removed from our study, as it was not included in the definition of capacity laid out in the new Mental Capacity Act (Department for Constitutional Affairs, 2005). Patients with capacity in all domains were defined as having overall capacity. Interview transcripts of the capacity assessments made by one of the two specialist registrars were assessed by a consultant psychiatrist (R.C.) who was unaware of the identity of the interviewer and interviewee, and the percentage agreement and interrater reliability between these assessments were calculated.

Data were entered onto the Statistical Package for the Social Sciences (SPSS) version 9.0 for Windows. $\chi^{2}$ and independent-samples $t$-tests were used to investigate the relationships between capacity and categorical and continuous variables respectively. A logistic regression analysis was employed to confirm independent predictors of capacity and to eliminate the confounding effects of variables.

\section{Results}

Initially a total of 93 patients were considered for entry into the study, of whom 26 were ineligible (12 did not have mania and 14 were considered to be in an insufficiently manic state). Fifty (75\%) of the 67 eligible patients completed the interview (Fig. 1). Agreement between clinicians was reached on $86 \%$ of the 200 items of capacity $(\kappa=0.68,95 \% \mathrm{Cl} 0.57-0.79)$. Nineteen of the 50 patients (38\%) were found to have overall capacity (Table 1).

The three domains of capacity were significantly related to each other: retain/understand, $\chi^{2}=12.347$, $P<0.001$; retain/weigh up, $\chi^{2}=22.727, P<0.001$; understand/weigh up $\chi^{2}=10.080, P=0.001$. There was no relationship between capacity and voluntary or detained status $\left(\chi^{2}=0.801, P=0.37\right)$, with approximately equal numbers of both groups of patients having capacity. Univariate analysis (Table 2) showed that capacity was predicted by prescription of a mood stabiliser, greater number of depressive episodes, lower YMRS score and higher IQ.

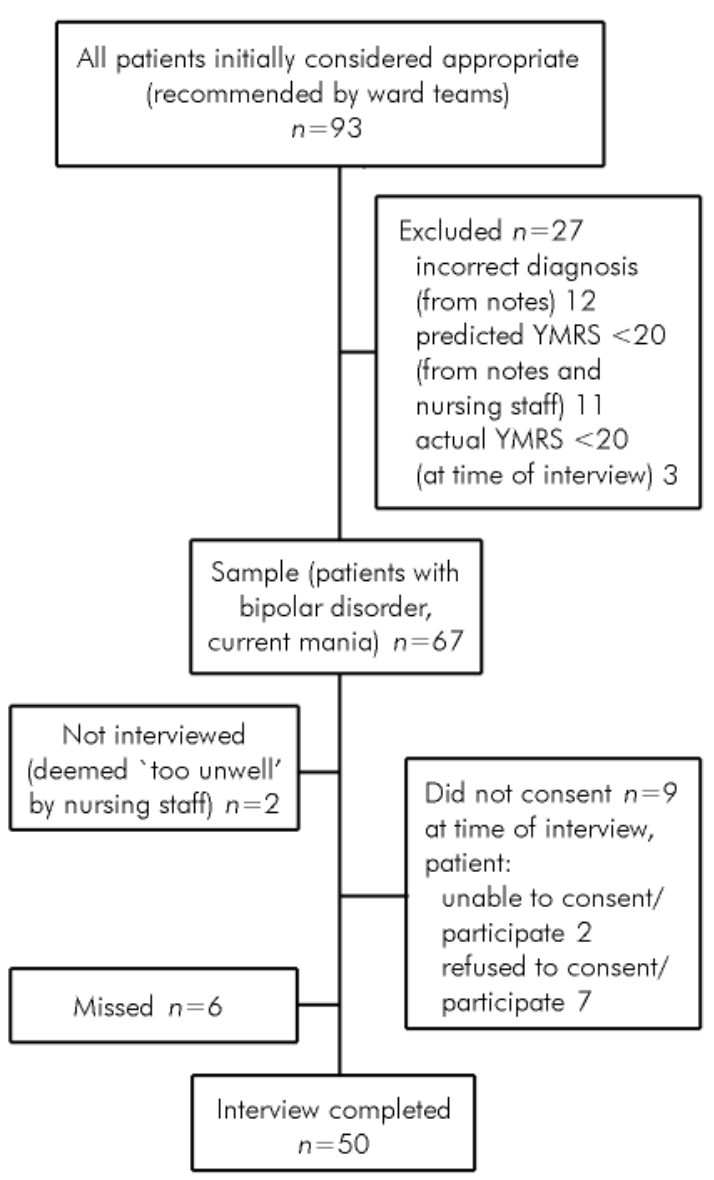

Fig. 1. Flow of participants through the study (YMRS, Young Mania Rating Scale).

Logistic regression analysis found the following variables to be independent predictors of capacity:

(a) increasing numbers of depressive episodes: for one to five depressive episodes the odds ratio was 82.2 (95\% Cl1.83-3695.0); for more than five depressive episodes, OR=878.4 (95\% Cl 2.76-279835.9);

(b) lowerYMRS scores: OR=0.65 (95\% Cl 0.44-0.96);

(c) higher IQ scores: $\mathrm{OR}=1.25(95 \% \mathrm{Cl} 1.02-1.52)$.

Prescription of a mood stabiliser was no longer a predictor of capacity. Owing to the small number of patients in each category of number of depressive episodes, the odds ratios here are not well estimated, highlighted by their magnitude and the width of the confidence intervals. In a separate analysis the correlation between number of depressive episodes and length of illness was not significant (Spearman's $r=0.227, P=0.143$ ).

\section{Discussion}

This study is the first to our knowledge that assesses capacity in patients with mania. It has a high inclusion rate, including the participation of a high proportion of severely unwell patients detained under the Mental Health Act. The main limitation of the study was the reliance on a clinical interview rather than the use of a standardised instrument for the assessment of capacity. 
Table 1. Patients with capacity according to domain and overall rating

\begin{tabular}{|c|c|c|c|c|}
\hline \multirow[b]{2}{*}{ Domain of capacity } & \multicolumn{2}{|c|}{ Patients with capacity } & \multicolumn{2}{|c|}{ Patients without capacity } \\
\hline & $n$ & $\%(95 \% \mathrm{Cl})$ & $n$ & $\%(95 \% \mathrm{Cl})$ \\
\hline Retain & 32 & $64(51-77)$ & 18 & $36(23-49)$ \\
\hline Understand & 22 & $44(30-58)$ & 28 & $56(42-70)$ \\
\hline Weigh up & 33 & $67(54-80)$ & 17 & $33(20-46)$ \\
\hline Communicate a choice & 49 & 98 & 1 & 2 \\
\hline Overall capacity & 19 & $38(22-51)$ & 31 & $62(49-75)$ \\
\hline
\end{tabular}

original papers

Table 2. Clinical and demographic associations with capacity

\begin{tabular}{|c|c|c|c|c|}
\hline Variable & All patients & $\begin{array}{c}\text { Patients with } \\
\text { capacity }\end{array}$ & Statistical test & $P$ \\
\hline \multicolumn{5}{|l|}{ Gender, $n$ (\%) } \\
\hline Male & $24(48)$ & $9(38)$ & $\chi^{2}=0.005$ & 0.94 \\
\hline Female & $26(52)$ & $10(38)$ & & \\
\hline Current mood stabiliser, $n(\%)$ & $33(66)$ & $16(49)$ & $\chi^{2}=4.5$ & 0.033 \\
\hline Current use of illicit drugs, $n(\%)$ & $12(24)$ & $3(25)$ & $\chi^{2}=1.1$ & 0.29 \\
\hline \multicolumn{5}{|l|}{ Alcohol, $n(\%)$} \\
\hline None & $29(60)$ & $11(38)$ & $\chi^{2}=1.6$ & 0.46 \\
\hline Below recommended limit & $10(21)$ & $5(50)$ & & \\
\hline Above recommended limit & $9(19)$ & $2(22)$ & & \\
\hline \multicolumn{5}{|l|}{ Education, $n(\%)$} \\
\hline No GCSES & $7(15)$ & $2(29)$ & $\chi^{2}=1.3$ & 0.72 \\
\hline GCSES & $15(31)$ & $7(47)$ & & \\
\hline A Level & $13(27)$ & $4(31)$ & & \\
\hline Higher education & $13(27)$ & $6(46)$ & & \\
\hline \multicolumn{5}{|l|}{ Previous manic episodes, $n(\%)$} \\
\hline None & $4(8)$ & 0 & $\chi^{2}=3.0$ & 0.22 \\
\hline $1-5$ & $17(35)$ & $8(47)$ & & \\
\hline$>5$ & $27(56)$ & $11(41)$ & & \\
\hline \multicolumn{5}{|l|}{ Previous depressive episodes, $n(\%)$} \\
\hline None & $21(47)$ & $2(10)$ & & 0.001 \\
\hline $1-5$ & $16(36)$ & $10(63)$ & & \\
\hline$>5$ & $8(18)$ & $5(63)$ & & \\
\hline \multicolumn{5}{|l|}{ Detained, $n(\%)$} \\
\hline Yes & $33(66)$ & $14(42)$ & $\chi^{2}=0.81$ & 0.37 \\
\hline No & $17(34)$ & $5(29)$ & & \\
\hline Age, years: mean (s.d.) & $42(13)$ & $42(12)$ & $t(50)=0.066$ & 0.95 \\
\hline YMRS score: mean (s.d.) & $29.0(7.0)$ & $25.5(5.4)$ & $t(48)=2.9$ & 0.005 \\
\hline IQ: mean (s.d.) & $109(10)$ & $114(7.5)$ & $t(38)=2.8$ & 0.008 \\
\hline Length of illness, years: mean (s.d.) & $16.1(10.4)$ & $16.3(8.4)$ & $t(50)=0.074$ & 0.94 \\
\hline
\end{tabular}

GCSE, General Certificate of Secondary Education; YMRS, Young Mania Rating Scale.

The interview used to assess capacity was based on two main sources: the Code of Practice of the Mental Health Act 1983 (Department of Health, 1999) and the guidance published by the British Medical Association and the Law Society (British Medical Association \& Law Society, 1995). A psychiatric interview by an experienced psychiatrist based on the above tests is at present the gold standard assessment of capacity in the UK. This study would have been strengthened by the co-administration of a structured assessment, for example the MacArthur Competence Assessment Tool for Treatment (Grisso et al, 1997).

In our study, although the capacity scores obtained in each domain were significantly related to one another, there was no evidence that the relationship between the domains was a hierarchical one. In practice this means there was no support for the concept that some domains of capacity are more basic than others, being relatively preserved, whereas others are more likely to be lost in individuals with more severe illness. Nearly all patients were able to communicate a choice, so this domain was not in any way discriminatory in the overall capacity assessment.

The finding that higher IQ predicted capacity suggests that intellectual ability is important in the ability to manipulate information about treatment. The inverse relationship between capacity and severity of mental 
7

original

papers illness has been further strengthened by this study. We found that increasing severity of manic symptoms predicted reduced capacity in patients with mania, a similar finding to that in schizophrenia, where severity of symptoms was related to reduced capacity (Grisso \& Appelbaum, 1995). It is unclear from our research which specific symptoms, for example delusions or conceptual disorganisation, have the greatest negative impact on capacity. The relationship between increased previous depressive (but not manic) episodes and the presence of capacity is more difficult to explain. One possible reason is the role of insight but this needs further investigation. Insight is predictive of capacity (Cairns et al, 2005) and may be linked with the tendency to develop depressive episodes in patients with bipolar disorder (Gonzales, 2005).

This study showed that there was no relationship between a patient's capacity to consent to acute drug treatment and that patient's status in hospital as voluntary or detained. This implies that in our patient sample capacity had either not been assessed or had not influenced the clinicians' decision to detain the patient compulsorily. This is in line with current mental health legislation in England and Wales, the Mental Health Act 1983, which is based on a 'status' test and a risk assessment rather than an assessment of capacity. This contrasts with the assessment of capacity required when considering the use of common law to treat patients with a physical disorder. It has been argued that there is no ethical justification for having separate and legally discriminatory legislation for those requiring treatment for a mental rather than a physical disorder (Eastman \& Dhar, 2000). Szmukler \& Holloway (2000) argued that a capacity test should form the basis of a decision to detain patients with mental disorder and that many clinicians would favour a new Mental Health Act based on capacity. Applying mental health legislation that included a capacity clause to the patients in this study would potentially have led to some additional patients being detained, treated compulsorily and afforded rights of appeal, and some of the detained patients not being detained at all.

In conclusion, this study found that less than half of in-patients with mania had capacity to consent to treatment and that their capacity was unrelated to informal or detained status. The capacity of patients with mania should be regularly reviewed and measures should be adopted to enhance it. Further research is needed to establish the clinical utility of standardised capacity assessment in this group, and to compare the capacity of patients with mania with other clinical groups.

\section{Declaration of interest}

None.

\section{Acknowledgements}

We thank Dr Sasha Francis who helped in recruiting patients and conducting some of the capacity interviews and Sarah White for her assistance in the statistical analysis of the data.

\section{References}

BRITISHMEDICAL ASSOCIATION \& LAW among individuals with serious menta SOCIETY (1995) Assessment of Mental Capacity: Guidance for Doctors and Lawyers. London: BMA.

CAIRNS, R., MADDOCK, C. BUCHANAN, A., et al (2005) Prevalence and predictors of mental incapacity in psychiatric in-patients. British Journal of Psychiatry, 187, 379-385.

DEPARTMENT FOR CONSTITUTIONAL AFFAIRS (2005) Mental CapacityAct. http://www.dca.gov.uk/menincap/ legis.htm

DEPARTMENT OF HEALTH (1999) Code of Practice to the Mental Health Act (1983). London: TSO (The Stationery Office

DEPARTMENT OF HEALTH (2004). Improving Mental Health Law. Towards a New Mental Health Act. London: TSO (The Stationery Office).

EASTMAN, N. \& DHAR, R. (2000) The role and assessment of menta incapacity: a review. Current Opinion in Psychiatry, 13, 557-561.

EASTWOOD, N. \& PUGH, R. (1997) Long-term medication in depot clinics and patients' rights: an issue for assertive outreach. Psychiatric Bulletin, 21, 273-275.

GELLER, J. L. (1982) State hospital patients and their medication: do they know what they take? American Journal of Psychiatry, 139, 611-615.

GONZALES, V. (2005) Association between suicide attempts and insight

illness. Dissertation Abstracts International: The Sciences and Engineering, 65, 5399.

GRISSO,T. \& APPELBAUM, P. S. (1995)

The MacArthur Treatment Competent Study. III Abilities of patients to consent to psychiatric and medical treatments. Law and Human Behaviour, 19, 149 174.

GRISSO,T., APPELBAUM, P. S. \& HILLFOTOUHI, C. (1997) The MacCAT-T: a clinical tool to assess patients capacities to make treatment decisions. Psychiatric Services, 48, 1415-1419.

NATIONAL INSTITUTE FOR CLINICAL EXCELLENCE (2002) Schizophrenia: Core Interventions in the Treatment and Management of Schizophrenia in Primary and Secondary Care. Clinical Guideline 1. London: NICE.

NELSON, H. (1982) National Adult Reading Test (NART): Test Manual. Windsor: nfer Nelson

SZMUKLER, G. \& HOLLOWAY, F. (2000) Reform of the Mental Health Act: health or safety? British Journal of Psychiatry, 177,196-200.

WORLD HEALTHORGANIZATION (1992) Tenth Revision of the International Classification of Diseases and Related Health Problems (ICD-10). Geneva: $\mathrm{WHO}$

YOUNG, R. C., BIGGS, J.T. \& ZIEGLER, V. E. (1978) A rating scale for mania: reliability, validity and sensitivity. British Journal of Psychiatry, 133, 429-435.

Jonathan Beckett Consultant Psychiatrist, South London and Maudsley NHS Trust, Lambeth Hospital, London, * Robert Chaplin College Research Unit, Royal College of Psychiatrists, London, and Directorate of General Adult Psychiatry, Oxfordshire Mental Healthcare NHS Trust, Littlemore Hospital, Oxford, email: rchaplin@cru.rcpsych.ac.uk 